\title{
Some Improvements of Ship Power Prediction Method in the IHI Towing Tank
}

\author{
by Tadaaki Yamasaki*, Member Takayuki Tsutsumi*, Member \\ Takatsugu Yokota*, Member Yukio Koshiba*, Member
}

\begin{abstract}
Summary
For further improvements of the ship power prediction method by model tests, there were many rooms to obtain the accuracy meeting the present designers' demands. In the IHI towing tank, since its establishment in 1966, steady achievements have been done to satisfy their demands. This paper presents almost all of the measures of improvements conducted and the results obtained in IHI, content of which extends from the facility and test practice to the model-ship correlation. Among them, first it is insisted that the reduction of influence of Reynolds number and disturbances such as the residual current in the tank upon the test results is quite effective for increasing accuracy. Second a theoretical estimation method of propeller open-water characteristics is proposed from the view point of correcting the influence of Reynolds number on its performance. Finally taking the influence of interference between Reynolds number of hull and the propeller loading into account, a new method of ship-model correlation for the effective wake is given. As a result, the average errors of model test results decrease less than $1 \%$ and the reliability of predicted ship power gets to more than $97 \%$.
\end{abstract}

\section{Introduction}

Since steam ships appeared, the fuel cost has held a major part in the operation expenditures. Especially, it became upto about $50 \%$ of them just after the oil crisis in 1973 and ship operators tried to save it with their best effort. But it is still more than $30 \%$ in spite of the low speed operation and fall in the price of fuel. The efforts of ship operators for the fuel saving have been directly reflected in ship yards. They adopt even such an improvement as its effect on the ship power is only $1 \sim 2 \%$ in the hull form design and obtain the effective gain of $5 \%$ or more by piling up such small improvements. Therefore, it becomes more necessary than as ever before to predict accurately the effect of hull form improvements on the ship power.

For predicting the ship power, there are three methods in substance. The first is the application of theories such as the wavemaking resistance theory, the second the use of the data base of formerly built ships and the third the method by means of the tank tests. Each has been used properly corresponding to the permissible allowance, time limit, expense and so on. In the above three,

* Ishikawajima-Harima Heavy Industries Co., Ltd. the last one has been thought to be most accurate and reliable. So it has been applied mainly to the power prediction for ships being built even though it takes more than three weeks and is highly expensive to obtain the results.

When W. Froude constructed the towing tank in 1871 at Torquay in England and measured the resistance of a model ship in the next year, it was begun to predict the ship power by means of the model tests. He also conducted the propeller open-water test and the behind test. He estimated the ship resistance from the model one according to the Froude's law and the propulsive coefficient by comparing the results of speed trials and the predicted ship resistances for formerly built ships ${ }^{11}$. His prediction method had been spreaded in the world. Though his method was founded on the Froude's law as in present, the correction of influence of Reynolds number on the model test results was inadequate. Then it became the principal problem in the practical works of ship power prediction. Many researches and improvements concerning this problem have been conducted since then in various towing tanks and discussions have been continued in the ITTC to make the prediction accuracy high.

During the first and second decades of this century, the self-propulsion test was developed as Schoenherr recollected his works in the discussion 
to Todd ${ }^{2}$. The ship power could be predicted directly from the torque and revolution of the model propeller, where the Gebers' friction correction was applied to the model hull. This method is still used in some towing tanks and we call this as the direct method, which is simple but not adequate to correct the influence of Reynolds number on the self-propulsion factors and propeller characteristics.

In 1932, Schoenherr proposed new formula based on the theory to estimate the friction resistance of so-called corresponding plank ${ }^{3}$. Hughes also proposed his formula in 1953 and introduced the concept of the form factor into the estimation of friction resistance of models and ships ${ }^{4), 5)}$.

Then the influence of Reynolds number on the hull resistance could be corrected more accurately than in the case of Froude's method. Concerning the propeller characteristics, Kempf suggested, in 1927, the influence of Reynolds number and roughness of the blade surfaces on $\mathrm{it}^{6)}$. Lerbs proposed, in 1951, a method to correct the scale and roughness effect on it $^{7}$. However, his method has not been applied widely to the daily ship power prediction. After the World War II, many experiments with actual ships were conducted mainly in Europe to study the influence of Reynolds number on the resistance and propulsive coefficient. The Lucy Ashton of BSRA $^{8)}$, the Victory ship of NSMB $^{9)}$ and the Meteor of $D^{2} G^{10)}$ were famous and typical experimental ships.

Since the latter half of 1950's, the size of hull started enlarging and its fullness was gradually increasing. Then the differences of the predicted ship power from the speed trial result exceeded so of ten the permissible allowance. The SR 41 committee was organized, in 1958, in the Ship Research Association of Japan to study the above problem, where the influence of Reynolds number on the effective wake was taken into account in the ship power prediction and a new prediction procedure, as a result, was proposed to achieve the subject ${ }^{11)}$. The proposed method is called as the analytical method. The SR 41 presented the wake ratio-a correction factor of the influence of Reynolds number on the effective wake-and also gave the new values of roughness allowance. Following after the SR 41, in 1961 Yokoo $^{12)}$ and in 1963 Taniguchi $^{18)}$ proposed their own power prediction practices and Taniguchi gave his diagrams for the roughness allowance and wake ratio, which were obtained by analysing the results of speed trials with the model test results for many ships formerly built.

The analytical power prediction method is thought to be advanced in comparison with the direct method because, in addition to the influence of Reynolds number on the hull resistance, that of self-propulsion factors and propeller characteristics can be considered. But it requires the supreme accuracy of measurements in the model tests. Taniguchi, Watanabe and Tamura of the Mitsubishi experimental tank made many endeavors to study the influence of Reynolds number on the self-propulsion factors and the propeller characteristics in addition to the hull resistance, to develop the precision instruments and to improve the test practices(4),15),18). Recently T. Sasajima pointed out the influence of the propeller loading on the effective wake and suggested the interactive influence of Reynolds number and the propeller loading on it $^{17)}$.

H. Sasajima and Tanaka proposed, in 1966, a new method to estimate analytically the influence of Reynolds number on the nominal wake ${ }^{18)}$, appropriateness of which was proved by the sea trials conducted by Namimatsu and others ${ }^{19)}$. In the period from 1950's to 1960's, series tests of propeller were conducted in many towing tanks. According to the results, the propeller charts were made for its design and the estimation of openwater efficiency ${ }^{20)}$,21) 22). Yokoo ${ }^{28)}$, Taniguchi24) and others investigated the influence of Reynolds number on the propeller characteristics but it was not revealed in detail at that time.

In 1966 the IHI towing tank was established, in which new devices and instruments were installed to obtain more accurate test results. Jin-naka, Tasaki and Yokota of IHI got good results for improving the practices of model tests(25),26),27) as Taniguchi and others of Mitsubishi had conducted. Yamasaki also studied the influence of Reynolds number on the propeller characteristics with large scale models, the diameter of which is $0.95 \mathrm{~m}$, and indicated that the lift on the propeller blades changes following after their surface boundary layer ${ }^{28)}$. In addition to the aboves, the refinement of the analytical method has been also conducted since its establishment.

Thus the scale effect on self-propulsion factors and propeller characteristics has been revealed so as the way mentioned above and the accuracy of test results has become to considerable level. So these leaded finally in 1978 to the result that the 15 th ITTC recommended the new power prediction method ${ }^{29)}$ based on the analytical method utilized in Japan.

However, many problems are remained in the model test practices and the correction of influence of Reynolds number, if it would be required to examine the effectiveness of hull and propeller improvements for the power saving of only $1 \sim 2 \%$. This paper presents mainly some results of IHI's following researches on enhansing the model test 
accuracy and correcting the influence of Reynolds number for the effective wake and the propeller characteristics to achieve the refinement of prediction method. The studies have been conducted particularly concerning single screw ships.

\section{Prediction of the ship resistance and its accuracy betterment}

\section{1 Prediction method}

To predict the ship power by means of the model test according to the analytical method, first of all the ship resistance should be estimated. Then the speed and resistance of model hull with the rudder are measured in the towing tank. The measured resistance of model is changed into nondimensional form with the model speed relative to water and its immersed volume $\nabla_{M}$. The result, which is called as the total resistance coefficient of model $r_{T, Y}$, consists of the viscous and wavemaking components, from which the form factor $K$ and the wavemaking resistance coefficient $r_{W}$ at various Froude numbers can be estimated by means of Hughes' method ${ }^{5}$.

Then if the air resistance coefficient and the roughness allowance are given by $r_{A}$ and $\Delta C_{F}$ respectively, the total resistance coefficient of ship $r_{T}$ is presented as follows

$$
r_{T}=(1+K) r_{F}+r_{W}+r_{A}+\left(S / 2 V^{2 / 3}\right) \Delta C_{F}
$$

where $S$ is the wetted surface area of ship. And the coefficients $r_{T}, r_{W}, \quad r_{F}$ and $r_{A}$ are defined as follows, i. e.

$$
\begin{aligned}
r_{T} & =\frac{R_{T}}{\rho \Gamma^{2 / 3} V^{2}} \\
r_{W} & =\frac{R_{W}}{\rho V^{2 / 3} V^{2}} \\
r_{F} & =\frac{S}{2 V^{2 / 3}} \cdot C_{F}
\end{aligned}
$$

$\frac{0.242}{\sqrt{ } C_{F}}=\log \left(C_{F} \cdot R_{n s}\right):$ Schoenherr's formula

$$
\begin{aligned}
& r_{A}=\frac{\rho_{A} A}{2 \rho V^{2 / 3}} \cdot C_{X} \\
& C_{X}=\frac{R_{A}}{\frac{1}{2} \rho_{A} A V^{2}}
\end{aligned}
$$

where $\rho$ and $\rho_{A}$ are the sea water and air densities at $15^{\circ} \mathrm{C}$ respectively. $R_{n s}$ is the ship hull Reynolds number. $A$ is the frontal projected area above the water surface. And $R_{T}, R_{W}$, and $R_{A}$ are the total resistance, the wave-making resistance and the air resistance of ship respectively. The friction resistance coefficient $C_{F}$ is estimated by using Shoenherr's formula in the IHI towing tank as given in the equations (2.4).

The air resistance $R_{A}$ can be obtained by the wind tunnel test. In this paper, the values of $C_{X}$ shown in Table 1 are used, which were the averaged ones of measured values by the Ship
Table 1 Values of air resistance coefficient $C_{X}$

\begin{tabular}{|l|c|c|}
\hline & Full Load & Ballast \\
\hline Tanker, Bulk Carrier & 1.1 & 0.9 \\
\hline General Cargo Ship & 0.7 & 0.6 \\
\hline Container Carrier & 0.8 & 0.8 \\
\hline Car Carrier & 0.9 & 0.7 \\
\hline
\end{tabular}

Research Institute. The roughness allowance $\Delta C_{F}$ will be decided in Chapter 5 comparing the model test results with the speed trial ones for several ships formerly built in IHI.

From the formulae (2.1) and (2.2), the total ship resistance $R_{T}$ at the ship speed $V$ is

$$
R_{T}=\rho V^{2 / 3} V^{2} r_{T}
$$

\subsection{Accuracy betterment}

For improving the accuracy of predicted ship resistance, first to decrease the measurement errors in the model tests, second to make the extrapolation formulae appropriate and third to estimate the roughness allowance properly are all indispensably valuable. As the extrapolation procedure, Hughes' method is thought to be the most proper one at present. Then in this paper, it is adopted as described before. Accuracy of $\mathcal{A} C_{F}$ is closely related to the first and second items in addition to the accuracy of speed trials.

Causes of the measurement errors in the model tests are related well to the tolerance of model manufacturing, bending and local strain of model hull, non-homogeneity of water temperature, current of tank water, air bubble clinging on the model hull surface, standing waves in the towing tank, breeding of microorganisms, steadiness of carriage speed, wind and its pressure by the carriage, accuracy of instruments, effectiveness of turbulence stimulators, estimation method of form factor and so on.

In the IHI towing tank, the tolerance of model hull manufacturing has been kept within the international standard, for example, as pointed out in the BTTP report ${ }^{30}$ and a wood-wax composite structure for the model hull was utilized to prevent the strain and bending of model ${ }^{31)}$. Two sets of the water purifier and the tank room with. out windows suppress well the breeding of microorganisms ${ }^{32)}$ and the former is also effective on homogenizing water temperature ${ }^{311}$. A precision current meter developed in IHI was installed at the distance of $3.5 \mathrm{~m}$ in front of the model bow, with which the speed of current is measured ${ }^{311}$. A deaerator was added to one of the water purifiers, which plays a definite role to prevent the air bubble clinging ${ }^{33)}$. A digitalized speed regulator was mounted on the towing carriage and it 


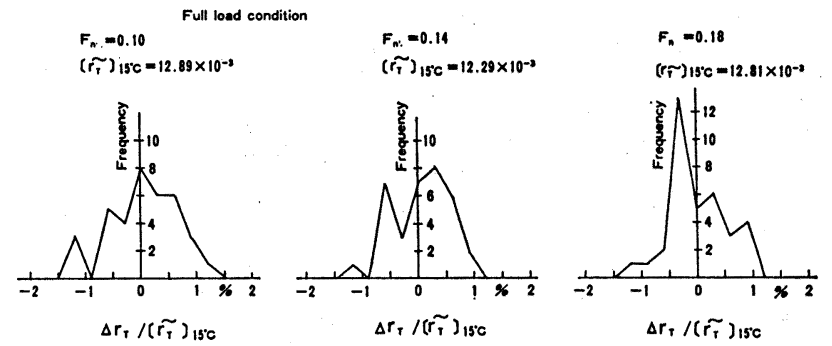

Fig. 1 Error of total resistance coefficient obtained by repeated test

decreases quite effectively the speed fluctuation of towing carriage ${ }^{32)}$. The digitalized data loggers were adopted. Then the errors in the data aquisition and processing stages become minimum ${ }^{32)}$. Turbulence stimulators have been heightened upto $3 \mathrm{~mm}$ to make their effect reliable. And Shirose's practice has been adopted for estimating the form factor $K$ in the lower speed range less than 0.1 of Froude number ${ }^{34)}$.

With the above mentioned countermeasures to the causes of error, the accuracy of towing test results has been improved upto necessary level. If it is acceptable to indicate the level of improvement with the coefficient of variation of the repeated test results which have been obtained by using the standard model of IHI since 1973, the values have become less than $0.5 \%$ for every Froude number as shown in Fig. 1, in which the mark $\sim$ denotes the meanvalue.

\section{Prediction of the self-propulsion factors of ship}

\subsection{Prediction method}

Following after the prediction of ship resistance, the self-propulsion factors of ship, i.e. the coefficient of thrust deduction $1-t$, coefficient of effective wake $1-w$ and relative rotative efficiency $\eta_{R}$, are predicted from those of model, which are obtained by the self-propulsion test. It should be carried out with the same model hull that was used in the resistance test and a stocked propeller whose dimensions are quite similar to the model of ship propeller. The characteristics of stocked propeller must be examined by the open-water test before the self-propulsion test is conducted.

In the test, the model hull speed relative to water $V_{M}$, the propeller revolution $n_{M}$, its thrust $T_{M}$ and torque $Q_{M}$ are measured under the conditions that the towing force $F_{T}$, which is based on Gebers' skin friction correction, is acting on the model hull and that the ground speed of model hull is kept entirely steady.

The self-propulsion factors of model, i. e. the coefficient of thrust deduction $1-t_{M}$, coefficient of effective wake $1-w_{M}$ and relative rotative efficiency $\eta_{R M}$, are estimated from the measured values. The latter two of them are obtained by using the thrust identity method.

On predicting the self-propulsion factors of ship, some assumptions on their scale effect are necessary. According to the preceding studies ${ }^{10)}{ }^{35}$ ), the scale effect of coefficient of thrust deduction and relative rotative efficiency is supposed to be as small as negligible. Then in this paper, the following assumptions are set up, i.e.

and

$$
1-t=1-t_{M}
$$

$$
\eta_{R}=\eta_{R M}
$$

However, the effective wake has so great scale effect that the correlation factor $E I$, which is called as the wake ratio, is also introduced into the prediction of ship effective wake taking the reciprocal of Taniguchi's wake ratio ${ }^{13)}$. Namely,

$$
1-w=E I\left(1-w_{M}\right)
$$

The wake ratio $E I$ has been estimated previously by calculating the wake ratios of many ships built formerly with the results of their speed trials and model tests and by analysing them statistically in consideration to Reynolds number, principal dimensions of ships and so on. Though this is one of the certain methods, the scatter of samples prevents the obtained wake ratio from necessary accuracy. In this paper, some improvements for the prediction of wake ratio will be conducted. The results will be presented in the next section.

\section{2 Accuracy betterment}

To improve the accuracy of predicting the selfpropulsion factors of ship, decrement of errors in the model tests and appropriate correction for the influence of Reynolds number, or scale effect, on the effective wake are necessary.

\subsubsection{Model test}

In the IHI towing tank, the following improvements of instrumentation and testing practice have been conducted for the former subject. First of all, the high precision propeller and self-propulsion dynamometers were developed ${ }^{31)}$, whose accuracy 


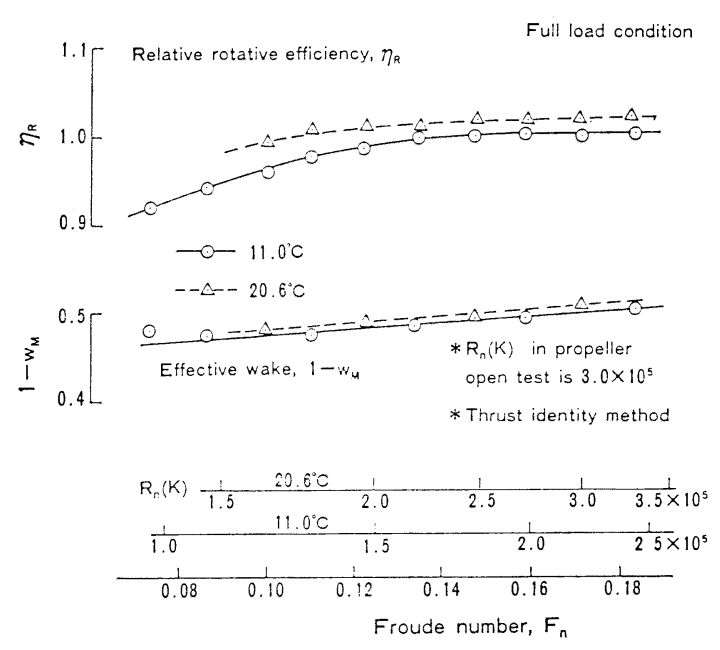

Fig. 2 Influence of water temperature, model speed and propeller Reynolds number on effective wake and relative rotative efficiency (Thrust identity method)
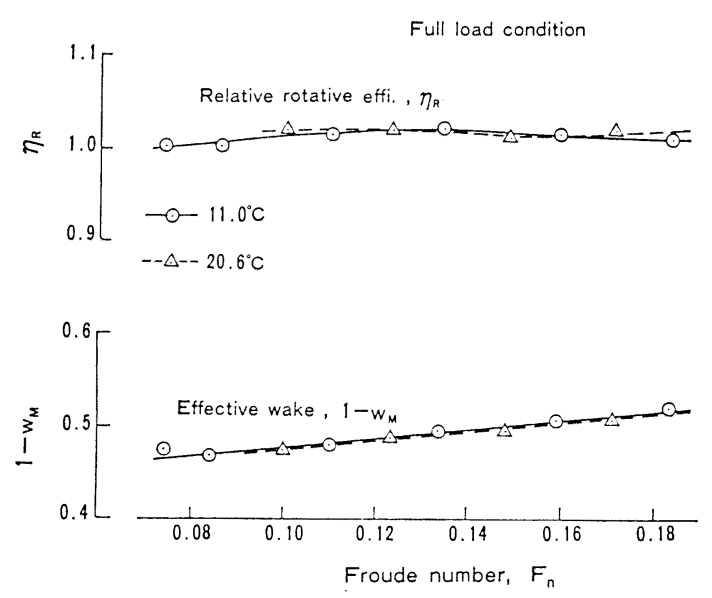

Fig. 3 Corrected effective wake and relative rotative efficiency (Thrust identity method)

is less than $0.1 \%$. Second, a new self-propulsion test practice composed by the hardware of the British method and the software of the continental method has been put into practical use to make the influence of model hull acceleration upon the propeller thrust and torque diminish ${ }^{27}$. And third, regarding the analysis of measured values, the open-water characteristics of stocked propeller at various Reynolds numbers have been used to remove the influence of propeller Reynolds number on the measured thrust and torque ${ }^{36)}$. The improvements described in the preceding chapter have been also achieved in the self-propulsion tests in addition to the aboves.

As a result of these improvements, scatters of measured values have become small. The effects of water temperature and model speed on the obtained self-propulsion factors were fairly removed. Examples are shown in Figs. 2 and 3, the values in which were obtained by using the standard models, of both hull and propeller, in the IHI towing tank.

The repeated tests with the standard models have been also conducted on the self-propulsion test to inspect the effectiveness of above improvements and the daily accuracy controls. A part of the results is shown in Fig. 4, in which the deviations of measured self-propulsion factors from their mean values are presented in the form of frequency polygons. The coefficients of variation are $0.7 \%$ for the coefficient of thrust deduction $1-t_{M}, 0.7 \%$ for the coefficient of effective wake $1-w_{M}$, and $0.6 \%$ for the relative rotative efficiency $\eta_{R, M}$. These values indicate that the accuracy of test results becomes to the same one as in the resistance test.

3.2.2 Correction of scale effect on the effective wake

When we predict the ship effective wake from the model test results, the scale effect on the effective wake is considered to be so great, as described before, that an appropriate correction is necessary. In this paper, it is assumed that the effective wake fractions of both the model and ship, $w_{M}$ and $w$, are mainly composed by the potential component and the viscous one. If the potential component is presented by suffix 0 and the viscous one by the suffix $V, w_{M}$ and $w^{\prime}$ can be given as a sum of the two, i. e.

$$
w_{M}=w_{M 0}+w_{M V}
$$

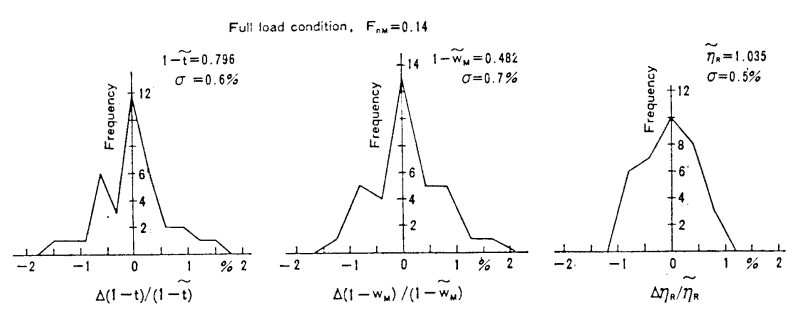

Fig. 4 Error of self-propulsion factors obtained by repeated test 
and

$$
w=w_{0}+w_{V}
$$

According to Freseneus ${ }^{37)}$, the potential component is assumed to be equal to the thrust deduction fraction $t$, which has no scale effect as assumed in the equation (3.1). Then the viscous one is assumed to be influenced by the viscous resistance of hull as H. Sasajima et al. indicated ${ }^{18)}$ and by the propeller loading as T. Sasajima et al. suggested $^{17)}$. H. Sasajima et al. presented the equation for correcting the scale effect on the nominal wake in the form of

$$
\frac{w_{V}^{\prime}}{w_{V M} M^{\prime}}=\frac{(1+K) r_{F}+\left(S / 2 V^{2 / 3}\right) \Delta C_{F}}{(1+K) r_{F M}}
$$

where' means the nominal wake. We apply the above equation to correcting the effect of hull viscous resistance on the viscous effective wake. Then taking the coefficient $k_{W}$, which is assumed to be varied only with the propeller loading, into account in order to correct its effect on the effective wake, we make a new equation for the effective wake by reforming (3.6). Namely,

$$
\frac{w_{V}}{w_{V M}}=\frac{(1+K) r_{F}+\left(S / 2 V^{2 / 3}\right) \Delta C_{F}}{(1+K) r_{F M}} k_{W}
$$

From the equations (3.1), (3.4), (3.5), (3.7) and Freseneus's assumption, the following equation is made for predicting the ship effective wake, i. e.,

$1-w=(1-t)+\left(t-w_{M}\right) \frac{(1+K) r_{F}+\left(S / 2 \nabla^{2 / 3}\right) \Delta C_{F}}{(1+K) r_{F M}} k_{W}$

Then the wake ratio is presented from the equation (3.3) and (3.8) as follows,

$E I=\frac{1-t}{1-w_{M}}+\frac{t-w_{M}}{1-w_{M}} \frac{(1+K) r_{F}+\left(S / 2 V^{2 / 3}\right) \Delta C_{F}}{(1+K) r_{F M}} k_{W}$

where $t, w_{M}, K$, can be obtained from the model test results, $r_{F}$ and $r_{F M}$ are calculated by means of Schoenherr's formula and $\Delta C_{F}$ may be estimated by using the speed trial results. As the coefficient $k_{\text {IV }}$, however, can not be estimated from only the model test results in present stage, we will obtain it by using the results of both the model tests and speed trials for formerly built ships, whose practical values will be presented in Chapter 5. As a result, it may be said that the coeffcient $k_{W}$ is selected as the model-ship correlation factor of effective wake instead of the wake ratio $E I$.

\section{Estimation of the open-water efficiency of ship propeller}

\section{1 Process of estimation}

Following after the estimation of resistance and self-propulsion factors, the prediction of open-water efficiency of ship propeller is necessary. As the necessary propeller thrust and its average advance speed at the working section can be estimated with the resistance and self-propulsion factors of ship, the load coefficient $K_{T} / J^{2}$ of ship propeller can be derived with them as follows.

$$
\frac{K_{T}}{J^{2}}=\frac{R_{T}}{\rho V^{2} D^{2}} \frac{1}{(1-w)^{2}(1-t)}
$$

where $D$ means the diameter of ship propeller.

In the mean time, if the open-water characteristics of ship propeller are given, its load coefficient $K_{T} / J^{2}$ at every advance coefficient $J$ can be calculated with the thrust coefficient $K_{T}$. Then, comparing the load coefficient given by the equation (4. 1) with the values obtained with the open-water characteristics, the corresponding efficiency and advance coefficient can be estimated through the comparison and the former gives the open-water efficiency of ship propeller.

\subsection{Estimation method of the open-water characteristics}

As stated above, the open-water characteristics of ship propeller are necessary to predict its openwater efficiency. Three methods can be adopted in present time. First, they can be obtained by conducting the open-water test for the model of ship propeller. Second, they can be predicted by inter- or extrapolation of values on the propeller charts which have been published. And third, they can also be estimated by the theoretical calculations.

These three methods are all available for the practical use, but each has some advantages and disadvantages. One of the most common disadvantages is the inadequate correction for the scale effect. In addition to this, the first method needs much money and many hours to achieve. The second method makes errors when the blade section, pitch distribution and blade contour are different from those of the propeller-charts. On the third method, it is not believed that the method gives accurate results for every kind of propellers, but the disadvantages which the first and second methods include in themselves can be removed and the scale effect may be corrected more easily than the other. Then in this paper, the theoretical calculation is applied to the estimation of openwater characteristics of ship propeller after reducing the above disadvantages.

\subsection{Theoretical estimation of the open-} water characteristics of ship propeller

Several methods have already been developed to estimate theoretically the open-water characteristics of propeller. The lifting surface theory is one of the most usual methods. In calculations, the lift reduction due to the viscosity of flow, i. e. the viscous component of lift, is considered somewhat empirically on the way or after the 
values in the potential flow are obtained. How. ever, it is supposed to be inadequate. The viscous drag is, of course, applied to each blade element.

On the other hand, regarding the two-dimensional aerofoils, Spence presented a theory to estimate the viscous component of lift. $\mathrm{He}$ considered it depends upon the boundary layer ${ }^{38)}$. His theory is thought to be one of the most appropriate ones when the estimated results are compared with those of experiment.

In this paper, the following practice is adopted to the estimation of open-water characteristics of ship propeller, to which the lifting surface theory, the equivalent profile method ${ }^{39,40)}$, the boundary layer theory and Spence's theory are applied. The equivalent profile method is adopted for the purpose to compare directly the calculated lift and drag with the experimental ones, though it is rather old-fashioned. The estimation process is described below.

First of all, let us calculate the open-water characteristics in the invicid flow by the lifting surface theory. In this paper Sugai's program ${ }^{41)}$ is used by making the lift slope coefficient 1.0. And let us assume that the results $J, K_{T 0}, K_{Q 0}$ correspond to those of the propeller working in the actual flow at infinite Reynolds number (in Kempf's definition). Then deciding the representative blade section of propeller at its $70 \%$ radius, let us calculate the potential component of lift $C_{L e 0}$ of so-called corresponding profile by the equivalent profile method.

In the next, let us consider the propeller working at finite Reynolds number $R_{n}(K)$ and denote the lift and drag coefficients of corresponding profile at the attack angle $\alpha_{e}$ with $C_{L e}$ and $C_{D e}$ respectively. It is assumed that the lift is consisted of the potential component and the viscous one and the former can be corresponded to the value $C_{L e 0}$ derived from $J, K_{T 0} ; K_{Q 0}$. When the latter is written with $C_{L e V}$ which is negative, the lift $C_{L e}$ at $\alpha_{e}$ can be presented by

$$
C_{L e}=C_{L e 0}+C_{L e V}
$$

The viscous component of lift $C_{L e V}$ and the drag $C_{D e}$ are assumed to be certainly smaller than the potential component of lift $C_{L e 0}$. We will estimate them in the following way by the application of boundary layer theory and Spence's theory for two-dimensional aerofoils, as stated above, and calculate the propeller open-water characteristics $J, \quad K_{T}, K_{Q}$ at $R_{n}(K)$ by means of the reversed application of equivalent profile method with $\alpha_{e}$, $C_{L e}$ and $C_{D e}$.

By the way, the lift slope of corresponding profile is a little different from that of the twodimensional aerofoil and is variable according to the aspect ratio of propeller blade. This may be

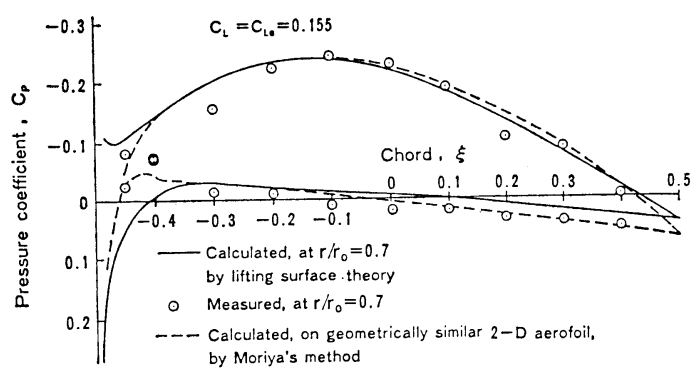

Fig. 5 Pressure distributions on representative section and its geometrically similar two-dimensional aerofoil

caused, as supposed, by the error of induced velocity in the equivalent profile method, which appears as the errors of attack angle $\alpha_{e}$. Therefore, $C_{L E V}$ and $C_{D e}$ can not be related to those of the two-dimensional aerofoil through the attack angle.

To avoid the above disadvantage, the following practice is set up in this paper, though a little complicated. Concerning the two-dimensional aerofoil, the boundary layer on it only depends upon its Reynolds number $R_{n}$ and the pressure distribution on its surfaces as indicated in the boundary layer theory. Its drag $C_{D}$ can be estimated empirically from its momentum thickness at the trailing edge according to Squire and Young ${ }^{42}$. Furthermore, Spence pointed out the viscous component of lift $C_{L V}$ can be calculated from the displacement thickness distributed on its surfaces and the boundary layer thickness at the trailing edge. As a result, both $C_{D}$ and $C_{L V}$ can be considered to be related only to its pressure distribution and its Reynolds number.

Meanwhile, the section lift coefficient at the representative section of propeller, which is estimated with the measured blade surface pressures, is quite identified with $C_{L e}$, which is estimated by means of the equivalent profile method with the open-water test results, at each attack angle ${ }^{40)}$. And the pressure distribution on the representative blade section is almost same to that of the twodimensional aerofoil with the same section shape when their lift coefficients are identified with each other as shown in Fig. 5.

According to the above results, if it can be also applied to $C_{L e V}$ and $C_{D e}$ of the corresponding profile of propeller that $C_{L V}$ and $C_{D}$ of the twodimensional aerofoil are only concerned with its pressure distribution and Reynolds number, the following assumptions can be presented. That is to say, let us consider a two-dimensional aerofil of the same section shape with the representative blade section of propeller-in short so-called here as the representative section foil-and denote the lift, its potential component, its viscous component, the 
drag and Reynolds number of the representative section foil with $C_{L}, C_{L 0}, C_{L V}, C_{D}$ and $R_{n}$ respectively. Then the following relation is assumed in the same way as for the corresponding profile.

$$
C_{L}=C_{L 0}+C_{L V}
$$

Between the corresponding profile and the representative section foil, if the relations

$$
R_{n}(K)=R_{n}
$$

and

$$
C_{L e 0}=C_{L 0}
$$

are realized, the following relations are assumed without any connections to the attack angles.

$$
\begin{aligned}
& C_{L e V}=C_{L V} \\
& C_{D e}=C_{D}
\end{aligned}
$$

Under these assumptions, the practical calculations start from estimating the pressure distribution on the representative section foil and its poten. tial component of lift $C_{L 0}$ at several attack angles by means of Moriya's method ${ }^{43)}$. According to the results, the boundary layers at $R_{n}$ can be estimated, in this paper, by means of Head and Green's method ${ }^{44)}$. So the drag $C_{D}$ is estimated by Squire and Young's method ${ }^{42)}$ and $C_{L V}$ is calculated by Spence's theory ${ }^{38)}$. The calculation formulae are presented in Appendix 1.

Since the values $C_{L 0}, C_{L V}, C_{D}$ at each attack angle $\alpha$ are all obtained, $C_{L V}$ and $C_{D}$ can be plotted with $C_{L 0}$ as abscissa and their mean lines can be drawn. Using these figures and the assumptions (4.4) (4.7), the viscous component of lift and the drag of corresponding profile, $C_{\text {LeV }}$ and $C_{D e}$, for each attack angle $\alpha_{e}$ can be estimated. If the obtained value of $C_{L e V}$ is substituted into the equation (4.2), the lift of corresponding profile at $R_{n}(K)$ is given. The propeller open-water characteristics at $R_{n}(K)$ can be calculated from the values of $\alpha_{e}, C_{L e}$ and $C_{D e}$ by the reversed application of the equivalent profile method as stated before.

When the turbulence stimulators are equipped or the roughness is distributed on the blade surfaces, the calculation of boundary layer is still so difficult that, in this paper, Reynolds number $R_{n}$ is corrected in the calculation in the way as presented in Appendix 2. The open-water characteristics obtained theoretically by the foregoing method are certainly agreed with the measured values of models on which the trip wires are equipped near the leading edge as the turbulence stimulators.

However, through many trials of the calculations, it is concluded that some empirical corrections for the zero-lift angle $\alpha_{Z e}$ of corresponding profile are necessary to obtain more accurate results. The correction can be conducted by adding the augment of zero-lift angle $\Delta \alpha_{z e}$ to $\alpha_{e}$, which

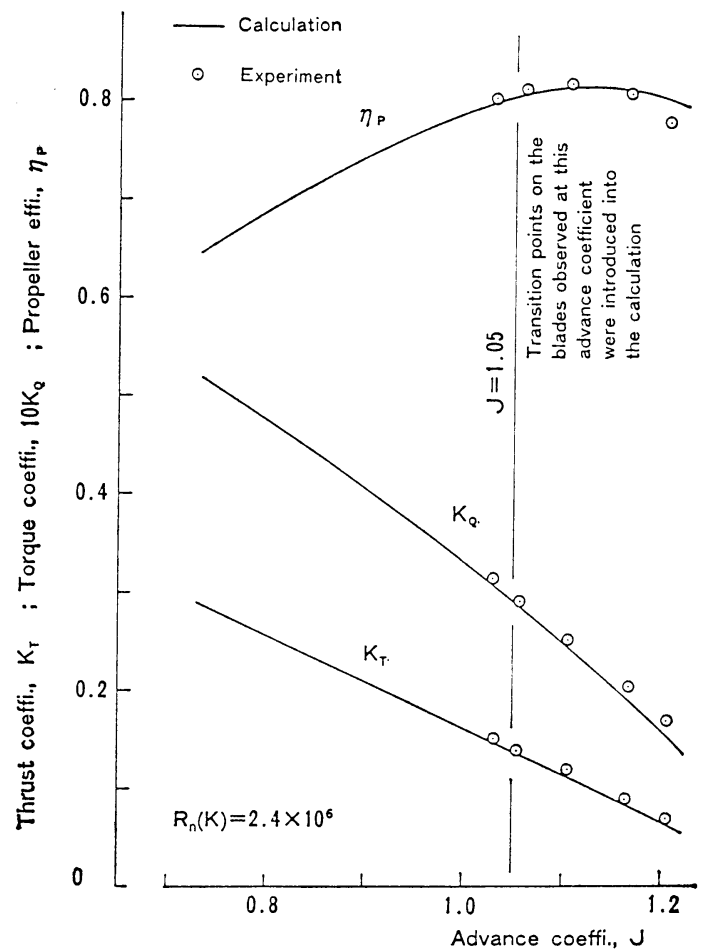

Fig. 6 Comparison between calculated and measured open water characteristics of large model propeller

is given by the sum of two different components, $\Delta \alpha_{Z e 1}$ and $\Delta \alpha_{Z e 2}$, i. e.,

$$
\Delta \alpha_{Z e}=\Delta \alpha_{Z e 1}+\Delta \alpha_{Z e 2}
$$

The former one $\Delta \alpha_{Z e 1}$ is related to the number of blades $Z$ and is empirically expressed as

$$
\alpha_{Z e 1}=0.25(Z-4)+0.1 \cdots \cdots \text { in deg. }
$$

The latter augment $\Delta \alpha_{Z e 2}$ is concerned with the shape of blade section and, for examples, its value is 0 for MAU section and 0.3 degrees for NACA 16 and 65 section. As a result, by the correction of zero-lift angle, the attack angle $\alpha_{e}$ becomes to $\alpha_{e}+\Delta \alpha_{z e}$ and then finally the estimated hydrodynamic characteristics of corresponding profile can be presented by $\alpha_{e}+\Delta \alpha_{Z e}, C_{L e}$ and $C_{D e}$.

\section{4 Examination of the calculated results with the measured ones}

In this section, the results calculated by the foregoing method will be examined with the test results for three arbitrary model propellers. The first example is concerning to a large scale model of four bladed MAU propeller whose diameter is $0.95 \mathrm{~m}$. In the test, the boundary layers of the back and face turned into turbulent one at the distance about $40 \%$ of chord length from the leading edge. This was taken into the calculation of its boundary layers. The calculated characteristics are agreed well with the measured ones as 

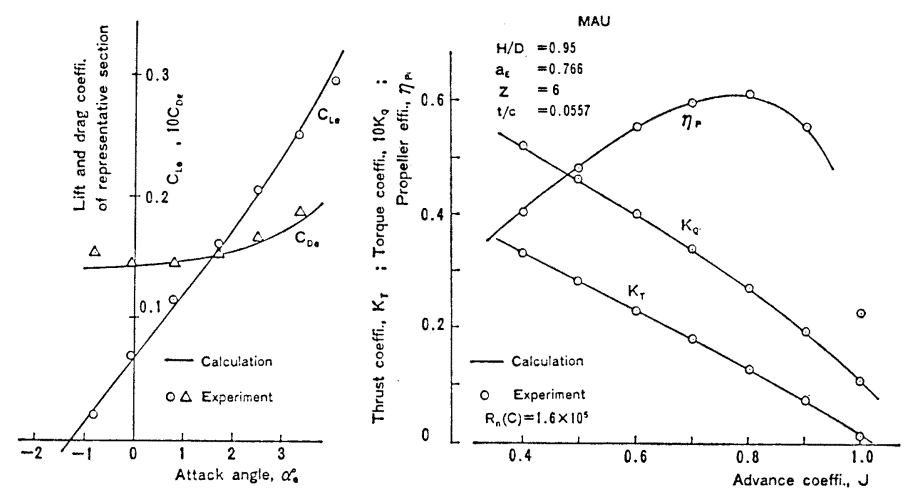

Fig. 7 Comparison between calculated and measured open water characteristics of ordinary model propeller with trip wires (1)
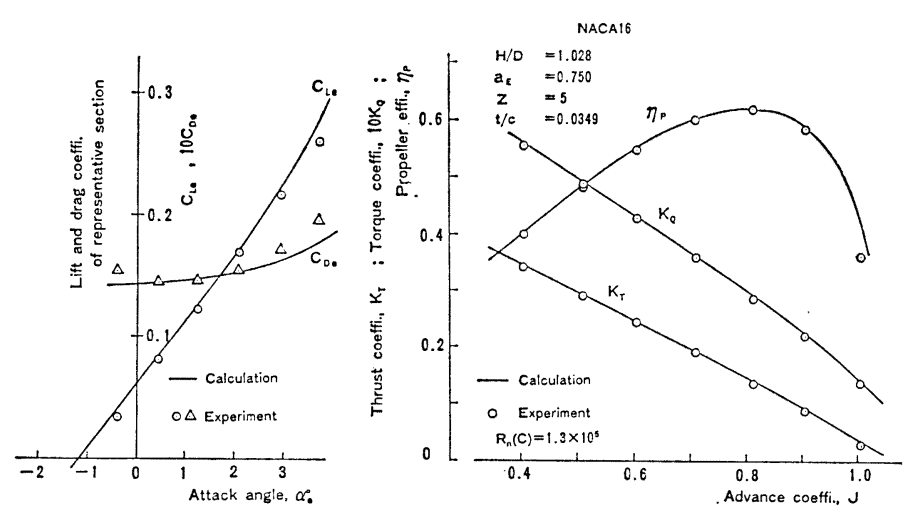

Fig. 8 Comparison between calculated and measured open water characteristics of ordinary model propeller with trip wires (2)

shown in Fig. 6, where both of the drag and the viscous component of lift are not so large due to the laminar boundary layer near the leading edges.

As the next example, a six-bladed MAU model propeller is treated here. The turbulence stimulators were equipped on its blades in the test. Then the boundary layers were thickened much, so that Reynolds number $R_{n}(K)$ was corrected in the boundary layer calculations with the measured minimum drag of corresponding profile by the method shown in Appendix 2. The calculated open-water characteristics are compared with the measured ones in Fig. 7. The fine identification is shown. Thirdly, a five-bladed NACA 16 propeller is examined as shown in Fig. 8. The same agreement as the MAU propellers is obtained. These examples indicate that the present method is utmost available to estimate the open-water characteristics of ship propellers with sufficient accuracy.

\section{Model-ship correlation factors}

\section{1 Roughness allowance}

In the foregoing chapters, some improvements of practice in the model tests, a new method of model-ship correlation for the effective wake and a theoretical method for estimating the open-water characteristics of ship propeller were presented. In this chapter, the values of roughness allowance $\Delta C_{F}$ and the model-ship correlation factor for the effective wake $k_{W}$ will be given by analysing the speed trial results of 10 ships with their model test results and with the theoretically estimated open-water characteristics of their propellers.

A part of the principal particulars of 10 ships and their propellers are presented in Table 2. As shown in the table, any multiple screw ships are not included in the selection but the size and kind of ships are in full of variety. The years in which they were built are also different in the period from 1965 to 1982.

The obtained values of $\Delta C_{F}$ are indicated in 
Table 2 Particulars of ships

\begin{tabular}{|c|c|c|c|c|c|c|c|c|c|c|}
\hline & A & $B$ & c & $D$ & $\mathbf{E}$ & F & G & $\mathrm{H}$ & I & $J$ \\
\hline Kind of ship* & $\mathrm{T}$. & c.c. & G.C. & T. & G.C. & B.C. & T. & T. & B.C. & T. \\
\hline Length & 300.0 & 177.4 & 157.0 & 360.0 & 157.0 & 260.0 & 320.0 & 277.6 & 232.0 & 175.0 \\
\hline Breadth & 50.0 & 27.6 & 22.0 & 62.0 & 26.4 & 43.0 & 60.0 & 48.0 & $41: 6$ & 32.2 \\
\hline Draft & 19.0 & 9.6 & 9.3 & 28.0 & 9.2 & 16.3 & 19.8 & 15.2 & 12.6 & 11.0 \\
\hline Block coefficient & 0.83 & 0.61 & 0.57 & 0.85 & 0.70 & 0.82 & 0.82 & 0.82 & 0.81 & 0.78 \\
\hline Prop. diameter $(m)$ & 9.16 & 6.32 & 6.50 & 9.24 & 5.51 & 7.74 & 8.53 & 2.60 & 7.18 & 6.20 \\
\hline Pitch ratio & 0.70 & 0.87 & 1.11 & 0.62 & 0.74 & 0.69 & 0.67 & 0.69 & 0.71 & 0.65 \\
\hline No. of blades & 5 & 4 & 4 & 5 & 4 & 5 & 5 & 5 & 5 & 4 \\
\hline Trial condition $\star \star$ & F & B & B & $F / B$ & B & B & $F$ & $E / B$ & B & $\mathbf{F}$ \\
\hline
\end{tabular}

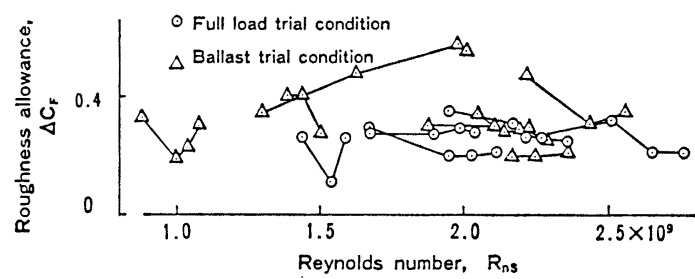

Fig. 9 Roughness allowance of various kind of ships

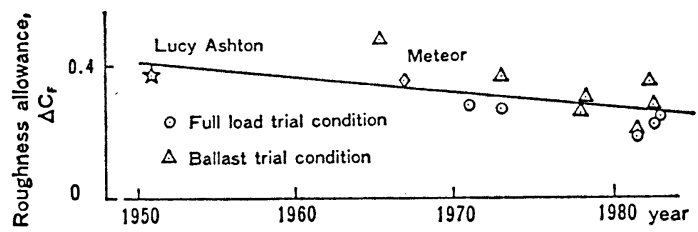

Fig. 10 Historical variation of roughness allowance

Fig. 9 with ship hull Reynolds number $R_{n s}$ as abscissa. Any relations between $\Delta C_{F}$ and $R_{n s}$ can not be observed in this figure. They are scattering in somewhat broad range, but this seems less when they are compared with those formerly published ${ }^{13), 45)}$. If the values of $\Delta C_{F}$ are closely related to the roughness of hull surface, as defined, the above scattering values may be allowable. Because the mean apparent amplitudes of hull roughness of many ships are distributed in the range to be comparable to the above, as presented in the BSRA report about the statistical analysis of hull roughness ${ }^{46), 47)}$. The report also points out that the hull roughness has been decreased from year to year. Then in order to observe the obtained $\Delta C_{F}$ from this point of view, the values of $\Delta C_{F}$ were averaged for each trial of each ship and the results are presented in Fig. 10. The values of the Lucy Ashton and the Meteor, which were

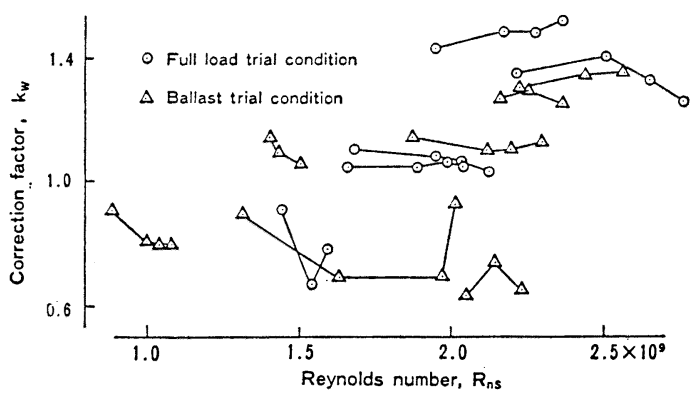

Fig. 11 Correction factor for effective wake of various kind of ships

thrusted by the jet engines, are added into the figure. They were obtained by reanalysing the results of sea trial with those of model test in the same way as the others. The mean line in Fig. 10 is drawn with the same slope as the rate of anual decrement of hull roughness which was given in the BSRA report and it is well matched to the anual change of roughness allowance obtained in present. Through the above surveys, there is every indication that the obtained $\Delta C_{F}$ correlates well with the hull roughness, though it is not cleared whether each value in Fig. 10 reflects correctly the hull roughness of each ship or not.

\subsection{Correlation factor for the effective wake}

As expressed in Section 3.3, the coefficient $k_{w}$ to correct the influence of interference between propeller loading and Reynolds number on the effective wake is adopted in this paper as one of the model-ship correlation factors. The values for the ships presented in Table 2 were estimated from the results of model test and speed trial by using the equation (3.8). The obtained values are presented in Fig. 11 with the hull Reynolds number as abscissa. They are distributed in the 


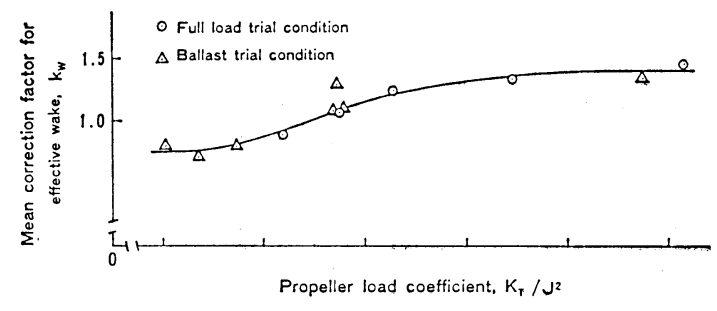

Fig. 12 Relation between correction factor for effective wake and propeller load coefficient

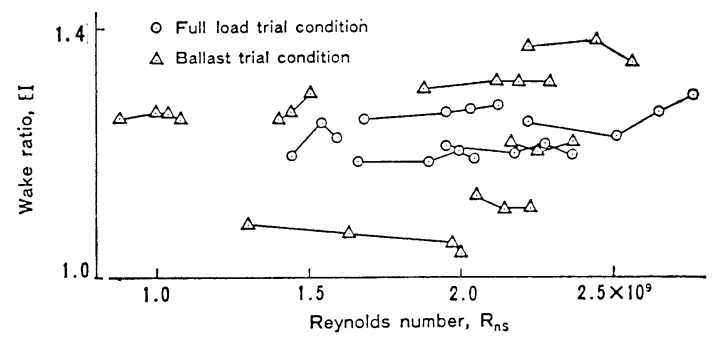

Fig. 13 Wake ratio of various kind of ships

broad range, but any influence of Reynolds number, kind of ships and their size on the values are not observed. When the values were averaged for each trial and the results are displayed with the propeller load coefficient $K_{T} / J^{2}$ as abscissa, a mean line can be easily drawn and the almost all of averaged values become to be distributed closely above and below it as shown in Fig. 12. This means that $k_{w}$ has close correlation with the propeller loading.

For reference, the wake ratios of sampled ships are given in Fig. 13 with the hull Reynolds number as abscissa. The values are much distributed in the range from 1.05 to 1.35. Any influences of the Reynolds number, kind of ships and their size on the wake ratios do not also appear in the figure. A mean line can not be given easily, so that the wake ratio is less appropriate for the model-ship correlation factor for the effective wake than $k_{w}$.

\section{3 Estimation of the correlation factors of ship being built anew \\ 5.3.1 $\Delta C_{F}$}

As the roughness allowance seems relating only to the hull roughness and the distribution of obtained values is supposed to be in the range of the ordinary hull roughness variation, an averaged value of $\Delta C_{F}$ of recently built ships is adopted here as the roughness allowance of new ships, which is assumed to be invariable according to the kind, size and loaded condition of ships. Then

$$
\Delta C_{F}=0.27 \times 10^{-3}
$$

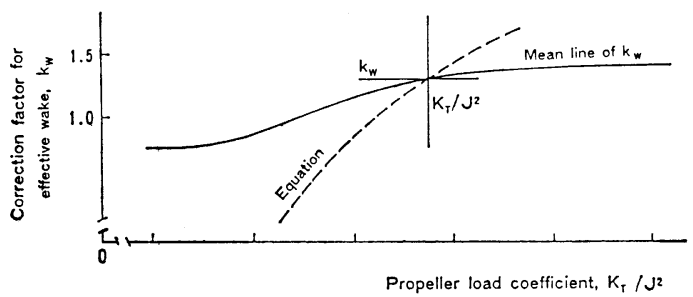

Fig. 14 Method to estimate correction factor for effective wake

\section{5. $3.2 k_{w}$}

When the coefficient of ship resistance $r_{T}$ is substituted in the equation (4.1) instead of $R_{T}$, the propeller loading coefficient $K_{T} / J^{2}$ can be expressed as follows.

$$
\frac{K_{T}}{J^{2}}=\frac{\nabla^{2 / 3}}{D^{2}} \frac{r_{T}}{(1-w)^{2}(1-t)}
$$

Then the ship effective wake can be presented from the above equation as follows.

$$
1-w=\frac{\Gamma^{1 / 3}}{D}\left(\frac{r_{T}}{1-t}\right)^{1 / 2}\left(\frac{J^{2}}{K_{T}}\right)^{1 / 2}
$$

Substituting the above into the equation (3.8), the following equation is obtained

$$
\begin{aligned}
k_{W} & =\frac{(1-t)-G_{1}\left(J^{2} / K_{T}\right)^{1 / 2}}{\left(w_{M}-t\right)} G_{2} \\
G_{1} & =\frac{\nabla^{1 / 3}}{D}\left(\frac{r_{T}}{1-t}\right)^{1 / 2} \\
G_{2} & =\frac{(1+K) r_{F M}}{(1+K) r_{F}+\left(S / 2 D^{2 / 3}\right) \Delta C_{F}}
\end{aligned}
$$

In the equation (5.4), $w_{M}, t$, and $r_{T}$ have been obtained by the model tests and $\Delta C_{F}$ has been decided with the value of $0.27 \times 10^{-3} . \quad r_{F M}$ and $r_{F}$ can be estimated by Schoenherr's formula.

Then the equation (5.4) becomes a simple function of $K_{T} / J^{2}$, which gives a curve that crosses the mean line of $k_{W}$ as shown in Fig. 14. In this paper, the value of $k_{w}$ at the cross point is adopted as the correlation factor for the effective wake of the ships being built anew.

\section{Ship power and the reliability ex- amination of predicted results}

\section{1 Ship power prediction}

In Chapter 2 the ship resistance, in Chapter 3 the self-propulsion factors, in Chapter 4 the propeller open-water efficiency and in Chapter 5 the model-ship correlation factors were obtained. Then the ship shaft horse power, $P_{S}$, can be presented as follows.

$$
\begin{gathered}
P_{S}=\frac{R_{T} V}{75} \frac{1}{\eta_{S}} \\
\eta_{S}=\frac{1-w}{1-t} \eta_{R} \cdot \eta_{P 0} \cdot \eta_{T}
\end{gathered}
$$

where $\eta_{T}$ means the transmission efficiency which is decided in general according to the location 


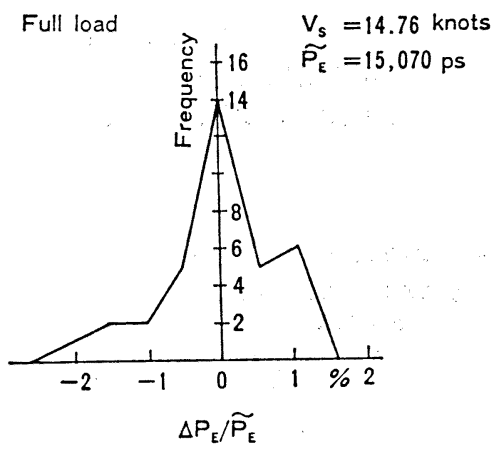

Fig. 15 Error of effective horse power obtained by repeated test

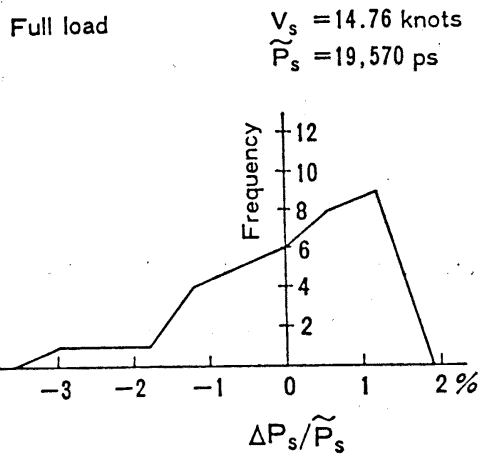

Fig. 16 Error of shaft horse power obtained by repeated test

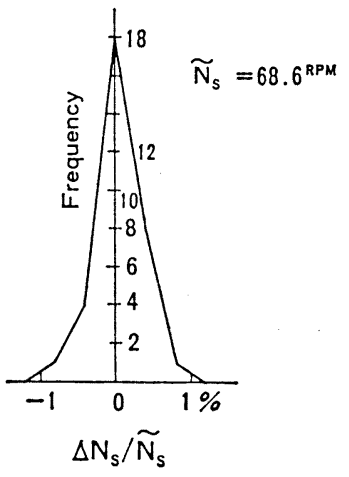

Fig. 17 Error of number of propeller rotation obtained by repeated test

of main engine. The revolution of ship propeller can be estimated by

$$
N=\frac{60(1-w) V}{J D} \text { in } \mathrm{rpm}
$$

where $J$ and $D$ mean the advance coefficient of ship propeller and its diameter respectively. The corresponding advance coefficient obtained in Chapter 4 should be substituted into the value of $J$ in the equation (6.2).

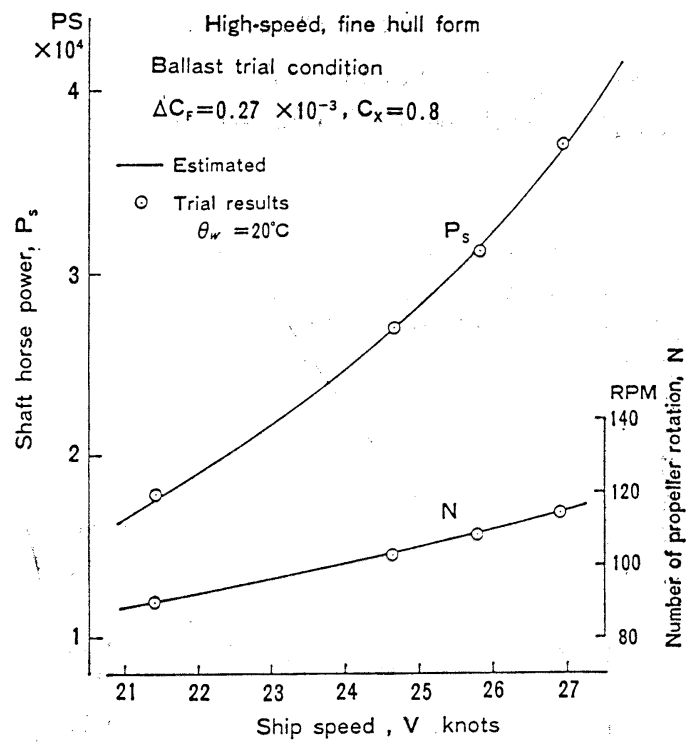

Fig. 18 Comparison between estimated horse power and trial result (1) (High speed ship)

\section{2 Deviations of the ship powers predicted} from the repeated test results

In this section the effect of foregoing improvements will be first examined by means of the deviations of ship power predicted from the repeated test results of standard model. Figs. 15, 16 and 17 show the frequency polygons of the deviation from the mean values regarding the predicted effective horse power, shaft horse power and propeller revolution respectively. Their coefficients of variation are $0.9,1.1$ and $0.3 \%$ respectively. These are all quite sufficient, though the shape of frequency polygon for the shaft horse power only seems somewhat different from the normal distribution.

\section{3 Comparison of the predicted shaft horse} power with the result of speed trial

Another examination will be achieved in this section by means of the comparison between the predicted horse power and the speed trial result about two ships, i. e., the one is a container carrier and the other is a very large crude oil carrier. They are selected arbitrarily and not included in Table 2. The results of each speed trial of each ship were corrected concerning wind and tide by means of Jin-naka's method ${ }^{48)}$. For predicting the shaft horse power, the surface roughness of each propeller was assumed to be $10 \mu \mathrm{m}$ in the ten-point height $h_{P V A}$ and the transmission efficiency is 0.97 for the container carrier and 0.98 for the crude oil carrier.

Fig. 18 shows the result of comparison for the container carrier, in which the predicted and mea- 
Low-speed, full hull form

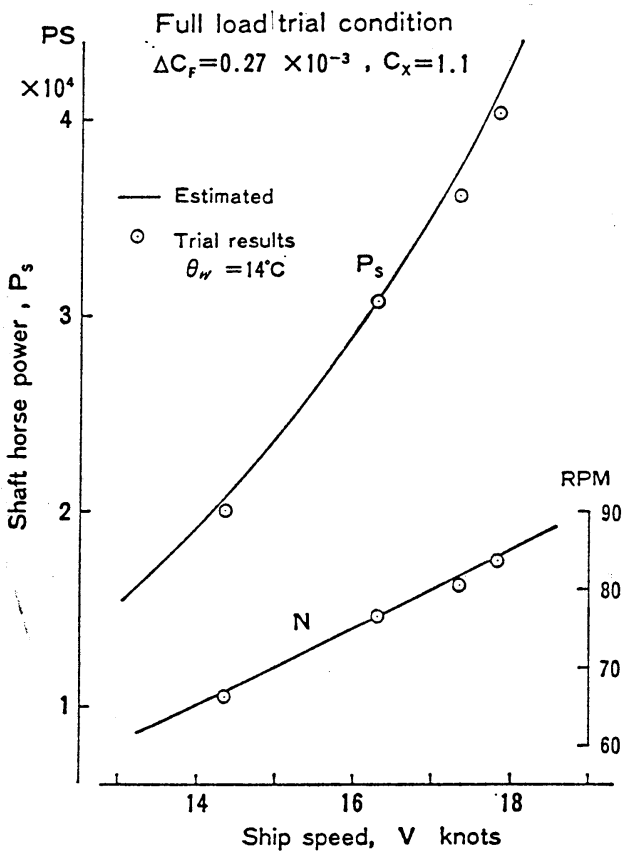

Fig. 19 Comparison between estimated horse power and trial result (2) (Tanker, full load)

sured values are quite agreed with each other. As presented in the figure, the sea water temperature at the trial was about 5 degrees higher than that in the prediction. The difference of temperature, however, corresponds to the error of only $1 \%$ for the shaft horse power and $0.3 \mathrm{rpm}$ for the propeller revolution.

Figs. 19 and 20 show the results about the fully loaded and ballasted conditions of the crude oil carrier respectively. In the fully loaded condition, the predicted shaft horse powers are about $3 \%$ larger, as a mean, than those measured at the speed trial. On the other hand in the ballasted condition they are about $2 \%$ smaller than the values at the speed trial. Some one may declare his opinion for the above errors to be insufficient to investigate in detail the propulsive performance of a ship being built anew, but these seem smaller than the errors, at least, which have appeared in the conventional predictions.

\section{Concluding remarks}

The authors presented some improvements of ship power prediction method conducted in the IHI towing tank. The measures extended from the facility and test practice to the model-ship correlation. As a result, the accuracy of predicted ship power attained to some satisfactory level meeting the present designers' demands. The summary

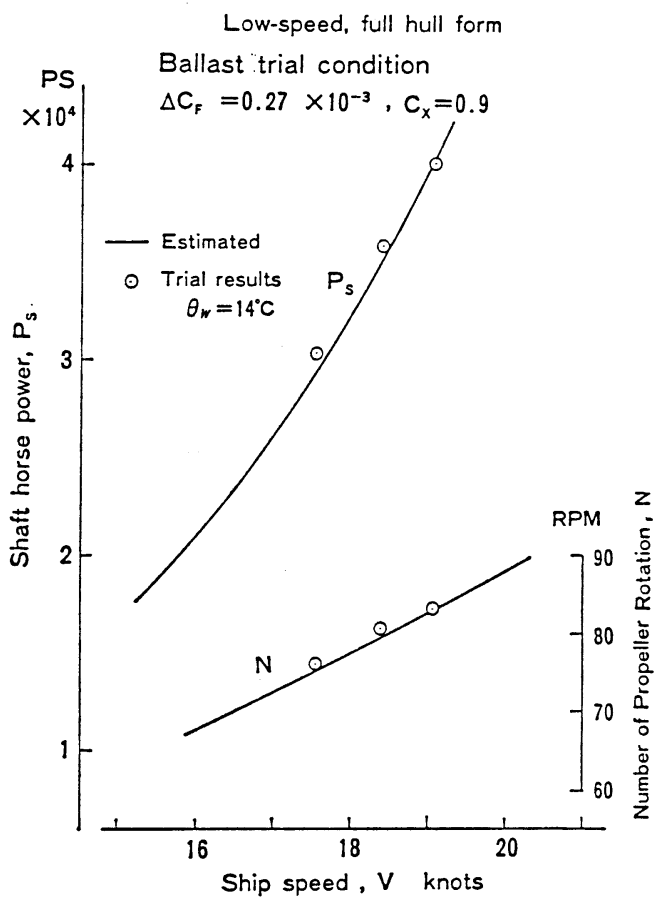

Fig. 20 Comparison between estimated horse power and trial result ( 3 ) (Tanker, ballast)

is as follows.

(1) The improvement of such the facilities as the auxiliary machineries, towing carriage, data processors, dynamometers are effective for the accuracy betterment of model test results.

(2) The removal or reduction of errors due to disturbances such as the circulation of tank water and the model hull acceleration is fundamental to increase the accuracy.

(3) The fine detection and sure correction of the influence of Reynolds number on such the measured results as the self-propulsion factors are essential demand in the model tests and make the errors in result decrease certainly.

(4) When these improvements were thoroughly put into practice, the results of repeated test indicated that the reliability of the measured values get to sufficient level and the coefficient of variation became less than $1 \%$ in the IHI towing tank.

(5) The theoretical estimation of the propeller open-water characteristics is one of the appropriate improvements from the view points of correcting the influence of Reynolds number on its performance and corresponding accurately the variation of its shape and particulars to the performance without rise of errors in the estimation.

(6) It makes the uncertainty of effective wake correlation reduce to some degrees to take the influence of interference between the propeller 
loading and Reynolds number on the effective wake in to account.

(7) The values of roughness allowance depend upon the hull surface roughness, which is somewhat widely different for each ship in present. This is one of the reasons why the accuracy of predicted ship power does not attain to the level of model test results. The regulation of hull surface roughness will be necessary in future to make the predicted ship power more reliable.

\section{Acknowledgement}

The studies presented in this paper have been carried out since the IHI towing tank was established in 1966. Professor Dr. R. Yamazaki has undertaken the task of teaching through the studies. Dr. H. Tanibayashi, the chairman of the ITTC performance committee, has encouraged the authors heartily. Professor Dr. T. Jin-naka has also guided the authors in their studies. Dr. R. Tasaki, Dr. M. Mori and Mr. M. Namimatsu have supported the authors' activities. Dr. Mori gave the authors many suggestions on the way of making the paper. All of research scientists and technicians in the IHI towing tank have cooperated to achieve the studies with their best effort. The authors appreciate all of them.

\section{References}

1) Gawn, R. W. L.: "Historical Notes on Investigations at the Admiralty Experiment Works, Torquay" Trans. I. N. A., (1941).

2) Todd, F. H.: "The Fundamentals of Ship Model Testing”, Trans. S. N. A. M.E., (1951).

3) Schoenherr, K. E.: "Resistance of Flat Surfaces Moving Through a Fluid", Trans. S. N. A. M. E., (1932).

4) Hughes, G.: "Frictional Resistance of Smooth Plane Surfaces in Turbulent Flow", Trans. I. N. A., (1954).

5) Hughes, G.: "Friction and Form Resistance in Turbulent Flow and a Proposed Formulation for Use in Model and Ship Correlation", Trans. I. N. A., (1954).

6) Kempf, G.: “Neuere Erfahrungen in Schiffbau Versuchswesen”, Jahr. S. T. G., (1927).

7) Lerbs, H.W.: "On the Effects of Scale and Roughness on Free Running Propellers", Jour. of the American Society of Naval Engineers, Vol. 63 (1951).

8) Conn, J.F.C. et al.: “B.S. R. A. Resistance Experiments on the Lucy Ashton. part-IIThe Ship-Model Correlation for the Naked Hull Conditions", Trans. I. N. A., (1953).

9) van Lammeren, W. P. A. et al.: "Scale Effect Experiments on Victory Ships and Models", Trans. I. N. A., Vol. 100 (1958).
10) Schuster, S. et al.: "Meteor-Messfarten 1967", Jahr. S. T. G., 62 Band, (1968).

11) The SR 41 Committee : Investigations into Propulsive and Steering Performances of Super Tankers", Report of the Japan Ship Research Association, No.31, (1960) (in Japanese).

12) Yokoo, K.: "An Investigation into Ship Model Correlation", Report of Transportation Technical Research Institute, No. 45, Oct. (1961).

13) Taniguchi, K.: "Model-ship Correlation Method in the Mitsubishi Experimental Tank”, Jour. of S. N. A. J., Vol. 113 (1963).

14) Taniguchi,K. et al.: "New Electric SelfPropulsion Test on a Tanker Model”, separate volume of Mitsubishi Zosen, (1960).

15) Watanabe, K.: "Repeated Self-Propulsion Test on a Tanker Model", Jour. of S. N. A. J., (1967).

16) Tamura, K.: "Study on the Blockage Correction", Jour. of S. N. A. J., (1972).

17) Sasajima, T. et al.: "Effect of the Contraction of Flow on Wake by the Propeller Suction", Proc. 14 th ITTC, (1975).

18) Sasajima, H. et al.: "Wake Distribution of Full Ships", Jour. of S. N. A. J., (1966) (in Japanese).

19) Namimatsu, M. et al.: "Wake Distribution of Ship and Model of Full Ship Form", Jour. of S. N. A. J., (1973) (in Japanese).

20) Tsuchida, K.: "Open Water Test Series with Modern Five-Bladed Propeller Models", Jour. of S. N. A. J., (1958).

21) Gawn, R. L. W.: "Effect of Pitch and Blade Width on Propeller Performance", Trans. I. N. A., (1953).

22) van Lammeren, W.P. A. et al.: "The Wageningen B-Series Screw Propellers", Trans. S. N. A. M. E., (1969).

23) Yokoo, K. et al.: "Some Scale Effect Experiments on Propeller", Proc. 9 th ITTC, (1960).

24) Taniguchi, K.: "Study on Scale Effect of Propulsive Performance by Use of Creosims of a Tanker", Jour. of S. N. A. J., (1966).

25) Jin-naka, T.: "Errors in Self-Propulsion Tests due to Acceleration of Model Ship", Proc. 12 th ITTC, (1969).

26) Tasaki, R. et al.: "Increase of Resistance due to Air Bubbles on the Surface of a Model Ship", Proc. 14 th ITTC, (1975).

27) Yokota, T.: "Improvement of Propulsion Test in the IHI Ship Model Basin”, IshikawajimaHarima Engineering Review, Vol. 14, No. 3, (1974) (in Japanese).

28) Yamasaki, T.: "On Some Tank Test Results 
with a Large Model Propeller-0.95 $\mathrm{m}$ in Diameter", Jour. of S. N. A. J., (1978).

29) Report of Performance Committee : Proc. 15 th ITTC, (1978).

30) British Towing Tank Panel : "Standard Procedure for Resistance and Propulsion Experiments with Ship Models", NPL Ship Division Report, No. 10, (1960).

31) Ishikawajima-Harima Heavy Industries Co., Ltd.: "15 Years of the IHI Towing Tank", Tokyo, (1982) (in Japanese).

32) Terao, T. et al.: "On the IHI Ship Model Basin”, Jour. of S. N. A. J., (1967) (in Japanese).

33) Yokota, T. et al.: "Effect of Air Bubble Clinging to Models in a Towing Tank and Measures for Prevention" ; Jour. of the Kansai Zosen Kyokai, Vol. 193, (1984) (in Japanese).

34) Shirose, Y. et al.: “A Method to Determine Form Factors of Ship Models from Resistance Tests" Ishikawajima-Harima Engineering Review, Vol.22, No.2, (1982) (in Japanese).

35) Nakatake, K. et al.: "Scale Effect on Propulsive Performance of a Full Ship”, Trans. W. J. S. N. No. 54, (1977) (in Japanese).

36) Yamasaki, T. et al.: "Accuracy of Model Test Results-Hull Form Development and Towing Tank" Textbook of JTTC Symposium, (1983) (in Japanese).

37) Freseneus, R.: “Das grundsatzliche Wesen der Wechselwirkung zwischen Schiffskoerper und Propeller", Schiffbau, Nr.10, XXIII, (1921).

38) Spence, D. A.: "Prediction of the Characteristics at Two-Dimensional Airfoils", Jour. of Aeronautical Science, Vol.21, No.9, (1954).

39) Lerbs, H. W.: "On the Effects of Scale and Roughness on Free Running Propellers", Jour. of American Society of Naval Engineers, Vol. 63 (1951).

40) Yamasaki, T.: "A Method for Estimating the Ship Propeller Characteristics", Trans. W. J. S. N., No.62, (1981).

41) Sugai, K.: "A Method for Calculating the Hydrodynamic Characteristics of Marine Propellers", Jour. of S. N. A. J., (1970) (in Japanese).

42) Squire, H. B. et al.: "The Calculation of the Profile Drag of Aerofoils", ARC, R\&M No. 1838, (1938).

43) Moriya, T.: "Theory of Aerodynamics", Baifu-kan, Tokyo, (1968) (in Japanese).

44) Cook, T. A.: "Measurements of the Boundary Layer and Wake of Two Aerofoil Sections at High Reynolds Numbers and High Subsonic Mach Numbers", ARC, R\&M No.3722,
(1971)

45) Watanabe, K. et al.: “Model-Ship Correlation-Hull Form Development and Towing Tank", Textbook of JTTC Symposium, (1983) (in Japanese).

46) Wellman, F.: "A Survey of Hull and Propeller Roughness Data", The Shipbuilder and Marine Engine-Builder, July, (1963).

47) Townsin, R. L. et al.: "Speed, Power and Roughness; The Economics of Outer Bottom Maintenance", Trans. R. I. N. A., (1980).

48) Jin-naka, T.: "On a Method of Analysis of Ship Speed Trial Results”, Trans. W. J.S. N., Vol. 64, (1982) (in Japanese).

\section{Appendix 1 An estimation method of the characteristics of two-dimensional aerofoils in the real fluid}

In order to estimate the lift and drag of a two-dimensional aerofoil in the real flow theoretically, at the start the velocity distribution on the aerofoil in the invicid fluid is calculated by means of Moriya's method ${ }^{43}$ as a first approximation. Secondly, using the results, the boundary layer on the aerofoil is estimated by means of Thwaites' method ${ }^{49)}$ for the laminar flow and Head. Green's method ${ }^{44)}$ for the turbulent flow. Thirdly, the wake in the downstream of aerofoil is estimated also by means of Head-Green's method. And then the drag and lift of aerofoil in the real fluid are calculated by means of Squire-Young's method $^{42)}$ and Spence's method ${ }^{38)}$ respectively. The practical calculation procedures are presented below.

\section{A 1. 1 Calculation of the velocity distribu- tion and the lift of aerofoil in the invicid fluid (Moriya's method)}

Let us consider a thin aerofoil in the uniform and invicid flow. For convenience, it is assumed that the inflow velocity and the chord length of aerofoil are a unit velocity and a unit length respectively. Let the nose-tail line of aerofoil be the $\xi$-axis, a line perpendicular to it be the $\eta$-axis and the middle between the nose and the tail be the origin.

Following after Moriya ${ }^{43)}$, let us express $\xi$ and $\eta$ with the $r, \theta$ system. The origin of the latter system is taken at that of the former one. Then the section shape of aerofoil is given by the following equations.

$$
\begin{gathered}
\xi=\frac{1}{2} \cos \theta \\
\eta=\sum_{n=1}^{\infty} A_{n} \cos n \theta+\sum_{n=1}^{\infty} B_{n} \sin n \theta
\end{gathered}
$$

The coefficients $A_{n}, B_{n}$ are calculated by the below equations, 


$$
\begin{aligned}
& A_{0}=\frac{1}{\pi} \int_{0}^{\pi} \eta_{m}(\theta) d \theta \\
& A_{n}=\frac{2}{\pi} \int_{0}^{\pi} \eta_{m}(\theta) \cos n \theta d \theta \\
& B_{n}=\frac{2}{\pi} \int_{0}^{\pi} \eta_{t}(\theta) \sin n \theta d \theta
\end{aligned}
$$

where $\eta_{m}$ and $\eta_{t}$ are the ordinate of mean camber line and the distribution of half thickness of aerofoil respectively. Then the velocity on the aerofoil is given by

$$
\begin{aligned}
V= & {\left[\operatorname { s i n } \alpha \left\{-\frac{1}{2}-\sum_{n=1}^{\infty} n B_{n}+\frac{1}{2} \cos \theta-\sum_{n=1}^{\infty} n A_{n} \sin n \theta\right.\right.} \\
& \left.+\sum_{n=1}^{\infty} n B_{n} \cos n \theta\right\}+\cos \alpha\left\{\sum_{n=1}^{\infty} n A_{n}-\frac{1}{2} \sin \theta\right. \\
& \left.\left.-\sum_{n=1}^{\infty} n A_{n} \cos n \theta-\sum_{n=1}^{\infty} n B_{n} \sin n \theta\right\}\right] \\
& \div\left[\frac{1}{4} \sin ^{2} \theta+\left\{-\sum_{n=1}^{\infty} n A_{n} \sin n \theta\right.\right. \\
& \left.\left.+\sum_{n=1}^{\infty} n B_{n} \cos n \theta\right\}^{2}\right]^{1 / 2}
\end{aligned}
$$

where $\alpha$ means the attack angle of aerofoil.

The velocity calculated by the equation (A 1.6) is considerably different from the measured value in the neighbourhood of trailing edge, so that in this paper the following approximations are used to obtain the velocity there. Let us first denote the velocities of upper surface, lower surface and trailing edge with $V_{1}(\xi), V_{2}(\xi)$ and $V_{T}$ respectively. Regarding the usual section shape, the measured velocity on the lower surface decreases almcst linearly from the mid-chord to the trailing edge and the calculated velocity is agreed with the measured one in the range from $\xi=0.35$ to 0.45 . Then in this paper the velocity of lower surface near the trailing edge is estimated approximately by using $V_{2} \quad(0.35)$ and $V_{2}(0.45)$ as follows.

$$
\begin{gathered}
V_{2}(\xi)=V_{2}(0.45)+\frac{V_{2}(0.45)-V_{2}(0.35)}{0.45-0.35}(\xi-0.45), \\
0.45 \leqq \xi \leqq 0.5 \quad \text { (A } 1.7)
\end{gathered}
$$

Then the velocity at the trailing edge can be denoted as

$$
V_{T}=V_{2}(0.5)
$$

Secondly, let us denote the velocity on the upper surface at $\xi=0.25$ and 0.35 with $V_{1}(0.25)$ and $V_{1}(0.35)$ respectively. There the calculated velocity is nearly agreed with the measured one. Let $a_{0} a_{1}$ and $a_{2}$ be the coefficients of the quadratic equation which gives the best fitted line concerning $V_{1}(0.25), V_{1}(0.35)$ and $V_{T}$. The value of these coefficients can be determined by means of the least squares method. Then the velocities on the upper surface nearly in front of the trailing edge can be estimated approximately by the following equation.

$$
V_{1}(\xi)=a_{0}+a_{1} \xi+a_{2} \xi^{2}
$$

In the next, the velocity in the downstream of aerofoil is approximated. In this paper, let us assume that the wake of aerofoil is carried away along the $\xi$-axis. Then following after the result of Cook's experiments ${ }^{44}$ about the static pressure on and behind the two-dimensional aerofoil, the velocity behind the aerofoil along the $\boldsymbol{\xi}$-axis, $V_{w}$, can be estimated by the following equation.

$$
V_{W}=1-\left(1-V_{T}\right) \cdot e^{-4.1(\xi-0.5)}, \xi \geqq 0.5
$$

Lastly, the lift coefficient, $C_{L 0}$, of aerofoil in the invicid flow is calculated by the following equation.

$$
C_{L 0}=4 \pi\left\{\sin \alpha\left(\frac{1}{2}+\sum_{n=1}^{\infty} n B_{n}\right)-\cos \alpha \cdot \sum_{n=1}^{\infty} n A_{n}\right\}
$$

\section{A 1.2 Calculation of the boundary layer and wake (Thwaites' and Head-Green's method)}

In this section, the boundary layer on the surface of aerofoil and the wake behind it are calculated by using the velocity distribution $V$ and $V_{w}$ in the invicid flow presented in the preceding section. First, let $\xi_{T R}$ be the transition point of boundary layer. Then the momentum thickness $\vartheta_{T R}$ of laminar boundary layer at $\xi=\xi_{T R}$ is calculated by means of Thwaites' method ${ }^{49)}$ as follows.

$$
\vartheta_{T R}{ }^{2}=\frac{0.45}{R_{n} \cdot\left[V^{6}\right]_{\xi=\xi T R}} \cdot \int_{-0.5}^{\xi T R} V^{5} d \xi
$$

where the pass way is taken along the $\xi$-axis instead of that along the aerofoil surface, because the aerofoil is assumed to be thin enough. $R_{n}$ means Reynolds number. When the inflow velocity, the chord length and the coefficient of kinematic viscosity of fluid are denoted with $W, C$ and $\nu$ respectively, $R_{n}$ is given by

$$
R_{n}=\frac{W \cdot C}{\nu}
$$

For the turbulent boundary layer, the momentum thickness $\vartheta$ and shape parameter $H$ are estimated by analysing Head-Green's differential equations numerically. The value of $\xi_{T R}$ is thought to be known in this paper. When the transition point is assumed to be at the leading edge, -0.47 is substituted into $\xi_{T R}$. (If $\xi_{T R} \leqq-0.47$, the result of differential equations diverges.) The initial value of momentum thicknesss is obtained by using the equation (A 1.12). And that of the shape parameter is assumed to be 1.3 at the transition point to simplify the calculation.

The differential equations for the turbulent boundary layer are expressed as follows.

$$
\begin{gathered}
\frac{d \vartheta}{d \xi}=\frac{1}{2} C_{f}-(H+2) \frac{\vartheta}{V} \cdot \frac{d V}{d \xi} \\
\vartheta \frac{d H_{1}}{d \xi}=F_{1}-H_{1}\left\{\frac{1}{2} C_{f}-(H+1)\right\} \frac{\vartheta}{V} \cdot \frac{d V}{d \xi}
\end{gathered}
$$

where $C_{f}, H_{1}$ and $F_{1}$ are given by the following 
equations.

$$
\begin{aligned}
& C_{f}=0.246 \cdot e^{(-1.561 H) R \vartheta^{-0.268}} \\
& R_{\vartheta}=\vartheta \cdot R_{n} \\
& H_{1}=2.5+1.609(H-1)^{-0.9066} \\
& F_{1}=0.0299\left(H_{1}-3\right)^{-0.6169}
\end{aligned}
$$

The differential equations for the wake behind the aerofoil are presented as follows.

$$
\begin{aligned}
\frac{d \vartheta}{d \xi} & =-(H+2) \frac{\vartheta}{V_{W}} \cdot \frac{d V_{W}}{d \xi} \\
\vartheta \frac{d H_{1}}{d \xi} & =F_{2}+H_{1}(H+1) \frac{\vartheta}{V_{W}} \cdot \frac{d V_{W}}{d \xi}
\end{aligned}
$$

where $F_{2}$ is obtained from following equations.

$$
\begin{aligned}
& F_{2}=K_{F} F_{W}+\left(1-K_{F}\right) F_{H} \\
& K_{F}=1-e^{(1-\xi) / 5 \delta_{T}} \\
& F_{W}=0.435(H-1)^{0.907} \\
& F_{H}=0.0299\left(H_{1}-3\right)^{-0.6169}
\end{aligned}
$$

$\delta_{T}$ in the equation (A 1.23) means the thickness of boundary layer at the trailing edge.

Using the equations from (A 1.12) to (A 1.25), the momentum thickness and the shape parameter of boundary layer and wake were estimated. In this paper the displacement thickness and the boundary layer thickness are given by the following equations.

$$
\begin{aligned}
\delta^{*} & =H \cdot \vartheta \\
\delta & =\frac{H(H+1)}{H-1} \cdot \vartheta
\end{aligned}
$$

Let us consider the trailing edge of aerofoil. When the momentum thickness of upper and lower boundary layers at the trailing edge are denoted with $\vartheta_{T 1}$ and $\vartheta_{T 2}$, and the shape parameters there with $H_{T 1}$ and $H_{T 2}$ respectively, the drag coefficient $C_{D}$ is estimated by means of SquireYoung's method ${ }^{42)}$. The practical equation for the estimation is presented below.

$$
C_{D}=2 \sum_{j=1}^{2} \vartheta_{T j} \cdot V_{T}\left(\frac{H_{T} j+5}{2}\right), j=1,2
$$

\section{A 1.3 Calculation of the lift of aerofoil in the real flow (Spence's method)}

Let us assume that the lift of aerofoil $C_{L}$ in the real flow can be given with a sum of the potential component $C_{L 0}$ and the viscous one $C_{L V}$ which is negative and that the former one is identified with the lift in the invicid flow. Then the lift $C_{L}$ can be expressed as follows.

$$
C_{L}=C_{L 0}+C_{L V}
$$

The viscous component $C_{L V}$ is calculated by means of Spence's method ${ }^{38)}$ as described below.

As the boundary layer grows on the upper and lower surfaces of aerofoil in the real flow, the vortices shed into the wake separately from the upper and lower boundary layers at the trailing edge. When the lift is steady, the sum of them should be zero. This condition is satisfied when the velocities at the external edge of upper and lower boundary layers are identified with each other at the trailing edge of aerofoil. These velocity is given approximately with a sum of velocities due to the inflow, the circulation and the boundary layer displacement thickness. Using the above condition Spence gave the rate of lift decrease due to the boundary layer ${ }^{38)}$. In this paper, the absolute viscous component of lift is obtained instead of the rate of lift decrease in his paper ${ }^{33)}$, though the process of calculation is according to his theory.

As expressed in Section A 1.1, let again the inflow velocity and the chord length be unit ones and let us give the section shape with the equations from (A 1.1) to (A 1.5). Further, the $\lambda, \theta$ coordinate system is introduced to express the flow field around the aerofoil. Namely,

$$
\xi+i \eta=\frac{1}{2} e^{(\lambda+i \theta)}
$$

Then the viscous component of lift is approximately estimated by the following equation.

$$
\begin{aligned}
C_{L V}= & \frac{-2 \pi}{\left(\frac{1}{\lambda_{T 1}}+\frac{1}{\lambda_{T 2}}\right)} \cdot\left\{1-\frac{G_{T 2}{ }^{2}+M_{T 2}{ }^{2}}{G_{T 1}{ }^{2}+M_{T 1}{ }^{2}} \cdot\left(\frac{\lambda_{T 1}}{\lambda_{T 2}}\right)^{2}\right. \\
& \left.\times \frac{m_{T 1}}{m_{T 2}}-2\left(v_{T 1}-v_{T 2}\right)\right\}
\end{aligned}
$$

where the suffixes 1 and 2 mean the upper and lower surfaces of aerofoil respectively. If the suffix is denoted with $j, j=1$ or $2, \lambda_{T j}$ is related to the thickness of boundary layer $\delta_{T j}$ at the trailing edge, and $G_{T j}, M_{T j}$ and $m_{T j}$ are given each with a function of $\lambda_{T j}$. And $v_{T j}$ is concerned to the displacement thickness of boundary layer. The equations for these values are presented below.

Let us first present the relation between $\delta_{T j}$ and $\lambda_{T j}$. When the section shape of aerofoil is given by the equations from (A 1.1) to (A 1.5) and the boundary layer thickness at the trailing edge $\delta_{T j}$ is measured perpendicularly to the $\xi$-axis, $\delta_{T j}$ can be expressed as follows.

$$
\begin{aligned}
\delta_{T} j= & \left(\frac{1}{2}+\sum_{n=1}^{\infty} n B_{n}\right) \sinh \lambda_{T j} \sin \lambda_{T j} \\
& -(-1)^{j}\left(\sum_{n=0}^{\infty} n A_{n}\right) \sinh \lambda_{T j} \cos \lambda_{T j} \\
& -(-1)^{j} \sum_{n=0}^{\infty} A_{n} e^{-n \lambda_{T j} \cdot \cos n \lambda_{T j}} \\
& +\sum_{n=1}^{\infty} B_{n} e^{-n \lambda_{T j} j} \cdot \sin n \lambda_{T j}, \quad j=1,2
\end{aligned}
$$

In the practical computation substituting the value of $\delta_{T j}$ into the equation (A 1.32), the value of $\lambda_{T j}$ can be obtained numerically by means of the iterative method.

Secondly, $G_{T j}$ and $M_{T j}$ in the equation (A 1.31) are given by a function of $\lambda_{T j}$ as follows.

$$
G_{T j}=\frac{1}{2}\left(\frac{1}{2}+\sum_{n=1}^{\infty} n B_{n}\right)
$$




$$
\begin{aligned}
& -\frac{1}{2} e^{-2 \lambda_{T j}} \cdot\left\{\left(\frac{1}{2}+\sum_{n=1}^{\infty} n B_{n}\right) \cos 2 \lambda_{T j}\right. \\
& \left.+(-1)^{j}\left(\sum_{n=1}^{\infty} n A_{n}\right) \sin 2 \lambda_{T j}\right\} \\
& +\sum_{n=0}^{\infty} n e^{-(n+1) \lambda_{T j}} \cdot\left\{(-1)^{j} \cdot B_{n} \sin (n+1) \lambda_{T j}\right. \\
& \left.+A_{n} \cos (n+1) \lambda_{T \jmath}\right\}, \quad j=1,2 \\
& M_{T j}=\frac{1}{2}\left(\sum_{n=1}^{\infty} n A_{n}\right) \\
& -\frac{1}{2} \cdot(-1)^{j} e^{-2 \lambda_{T j}} \cdot\left\{\left(\frac{1}{2}+\sum_{n=1}^{\infty} n B_{n}\right) \sin 2 \lambda_{T j}\right. \\
& \left.-(-1)^{j}\left(\sum_{n=0}^{\infty} n A_{n}\right) \cos 2 \lambda_{T j}\right\} \\
& -\sum_{n=0}^{\infty} n e^{-(n+1) \lambda_{T j}} \cdot\left\{(-1)^{(j+1)} \cdot B_{n} \sin (n+1) \lambda_{T j}\right. \\
& \left.+A_{n} \cos (n+1) \lambda_{T \jmath}\right\}, \quad j=1,2
\end{aligned}
$$

And third, $m_{T j}$ in the equation (A 1.31) is expressed with a function of the parameter $\lambda_{T j}$ and the attack angle $\alpha$ as follows.

$$
\begin{aligned}
m_{T j}= & 1-\lambda_{T j}\left\{2+(-1)^{j} \tan \left(\alpha-\alpha_{Z 0}\right)\right\} \\
& +2 \lambda_{T j^{2}}\left\{1+(-1)^{j} \tan \left(\alpha-\alpha_{Z 0}\right)\right\} \\
& -\frac{2}{3} \lambda_{T j^{3}}\left\{2+(-1)^{j} \tan \left(\alpha-\alpha_{Z 0}\right)\right\} \\
& +\frac{16}{9} \lambda_{T j^{4}}, \quad j=1,2
\end{aligned}
$$

where $\alpha_{Z 0}$ means the attack angle at the zero-lift in the ideal flow, which can be expressed by means of Moriya's theory ${ }^{43)}$ as follows.

$$
\alpha_{Z 0}=\tan ^{-1}\left\{\sum_{n=1}^{\infty} n A_{n} /\left(\frac{1}{2}+\sum_{n=1}^{\infty} n B_{n}\right)\right\}
$$

$v_{T j}$ in the equation (A 1.31) is related to the displacement thickness of boundary layer $\delta_{j}^{*}$, as stated above, which presents the influence of disturbances due to $\delta_{j}{ }^{*}$ of both boundary layer and wake on the velocity at the external edges of boundary layer at the trailing edge of aerofoil. This can be also expressed approximately according to Spence's theory ${ }^{38)}$. Namely,

$$
v_{T \mathfrak{j}}=\int_{-\pi / 2}^{\pi / 2}\left(\frac{\delta j^{*}}{\delta T^{j}}\right) \cos 2 \chi d \chi, \quad j=1,2
$$

where $\delta_{T j}$ means the boundary layer thickness at the trailing edge and a parameter $\chi$ is related to $\xi$. On the aerofoil surfaces, the value of $\chi$ is calculated by the following equation.

$$
\begin{aligned}
\tan \chi= & \frac{\cos \left\{\cos ^{-1} 2 \xi-\left(\alpha-\alpha_{Z 0}\right)\right\}}{\lambda_{T j^{2} \cos \left(\alpha-\alpha_{Z 0}\right)}} \\
& -\frac{\left(\cos ^{-1} 2 \xi\right) \sin \left(\alpha-\alpha_{Z 0}\right)+\cos \left(\alpha-\alpha_{Z_{0}}\right)}{\lambda_{T j^{2}} \cos \left(\alpha-\alpha_{Z 0}\right)}
\end{aligned}
$$

In the wake, the value of $\chi$ can be presented as follows.

$$
\tan \chi=\frac{\cosh \lambda \cos \left(\alpha-\alpha_{Z_{0}}\right)-\cos \left(\alpha-\alpha_{Z_{0}}\right)}{\lambda_{T j}{ }^{2} \cos \left(\alpha-\alpha_{Z 0}\right)}
$$

As the parameter $\lambda$ is a function of only $\xi$ on the $\xi$-axis in the wake, the relation between $\xi$ and $\lambda$ is expressed as follows.

$$
\xi=\left(\frac{1}{2}+\sum_{n=1}^{\infty} n B_{n}\right) \cosh \lambda-\sum_{n=1}^{\infty} n B_{n} e^{-n \lambda}
$$

Using the equations (A 1.38), (A 1.39) and (A 1. 40), the relation between $\chi$ and $\xi$ can be obtained both on the aerofoil surface and along the $\xi$-axis in the wake. Then the integration (A 1.37) can be numerically calculated and the influence of displacement thickness on the velocity at the trailing edge can be estimated.

In this way mentioned above, if the values of $\delta_{T j}$ and $\delta_{j}{ }^{*}$ are estimated by means of the method presented in Section A 1.2, the values of $\lambda_{T j}$, $G_{T j}, M_{T j}, m_{T j}$ and $v_{T j}$ can be all calculated. Therefore, substituting these values into the equation (A 1.31), the viscous component of lift coefficient $C_{L V}$ can be estimated.

\section{Reference}

49) Thwaites, B.: "Approximate calculation of the laminar boundary layer", Aero. Quart., (1949).

\section{Appendix 2 A definition of the corrected Reynolds number}

Let us consider an aerofoil in the real flow. And let $C, t, W$ and $\nu$ be its chord length, maximum thickness, inflow velocity and coefficient of kinematic viscosity of fluid respectively. If the surface of aerofoil is smooth and the boundary layer on its surfaces changes naturally into turbulent one at the leading edge, the minimum drag coefficient of aerofoil can be estimated empirically by means of the following equation ${ }^{50)}$.

$$
\left[C_{D}\right]_{\min }=2 C_{F}\left(1+2 \frac{t}{C}\right)
$$

where $C_{F}$ means the coefficient of turbulent friction resistance of corresponding plank. In this paper, it is estimated by Prandtl-Schlichting's formula following after the tradition. Namely,

$$
C_{F}=0.455\left(\log R_{n}\right)^{-2.58}
$$

where $R_{n}$ means Reynolds number, i.e.,

$$
R_{n}=\frac{C \cdot W}{\nu}
$$

Substituting the equation (A 2.3) into the equation (A 2.2) and deforming it, the following equation is obtained

$$
R_{n}=\exp 2.30\left\{\frac{0.91\left(1+2 \frac{t}{C}\right)}{\left[C_{D}\right]_{\min }}\right\}^{1 / 2.58}
$$

Thus if $\left[C_{D}\right]_{\text {min }}$ is given when the turbulent boundary layer develops from the leading edge naturally, the Reynolds number corresponding to it can be approximately estimated by the equation (A 2. 4).

When Reynolds number $R_{n}$ is small, the laminar boundary layer remains on the aerofoil surfaces, 
which makes the estimation of boundary layer thickness difficult. In this case, small turbulent stimulators are sometimes equipped on the upper and lower surfaces near the leading edge in the experiments. Then the boundary layer becomes turbulent at the stimulators even at small $R_{n}$ of about $1 \times 10^{5}$. But its thickness and the drag increase a little in comparison with those in the case that the boundary layer is supposed to be turbulent from the leading edge at $R_{n}$ without the stimulators.

Then let $\Delta C_{D}$ be the increment of minimum drag coefficient. Substituting $\left[C_{D}\right]_{\min }+\Delta C_{D}$ into the equation (A 2.4) instead of $\left[C_{D}\right]_{\mathrm{min}}$, the value of $R_{n}$ becomes a little smaller. If the rate of decrease is denoted with a coefficient $k_{R}$, it is given as follows.

$$
k_{R}=\exp \left\{-0.86\left(1+2 \frac{t}{C}\right)^{0.388} \cdot\left[C_{D}\right]_{\min }^{-1.388} \cdot \Delta C_{D}\right\}
$$

In the next, let us define $R_{n}(C)$ with the following equation.

$$
R_{n}(C)=k_{R} \cdot R_{n}
$$

Here $R_{n}(C)$ is named the corrected Reynolds number. And it is assumed that the state of boundary layer on the aerofoil surfaces with the turbulent stimulators is equivalent to that of the aerofoil without stimulators, Reynolds number of which is thought to be decreased with the rate of $k_{R}$. Then the boundary layer of aerofoil with the turbulent stimulators at $R_{n}$ can be approximately estimated by means of the boundary layer theory at $R_{n}(C)$ instead of $R_{n}$.
When the small roughness of $5 \sim 10 \mu \mathrm{m}$ is distributed on the aerofoil surfaces as on the propeller blades, the above method is also applied to estimate the boundary layer thickness. In this case, if the roughness height $k_{S}$ is known, the minimum drag coefficient is first estimated by using PrandtlSchlichting's formula for the rough plank. Namely,

$$
\left[C_{D S}\right]_{\min }=2\left(1+2 \frac{t}{C}\right) \cdot\left(1.89+1.62 \log \frac{C}{k_{S}}\right)^{-2.5}
$$

where the above equation is valid when $C / k_{S}$ is in the range between $10^{2} \sim 10^{6}$. As $\left[C_{D S}\right]_{\min }$ is larger than $\left[C_{D}\right]_{\mathrm{min}}$ given by the equation (A 2.1), the difference $\Delta C_{D}$ is denoted as follows.

$$
\Delta C_{D}=\left[C_{D S}\right]_{\mathrm{min}}-\left[C_{D}\right]_{\mathrm{min}}
$$

Then substituting $\Delta C_{D}$ into the equation (A 2.5), the coefficient $k_{R}$ is estimated. Substituting $k_{R}$ into the equation (A 2.6), the corrected Reynolds number can be obtained. When the roughness height of surface is presented with the so-called ten-point height, the relation between $k_{S}$ and the ten-point-height $h_{P V A}$ is approximately given by the following equation ${ }^{46), 51)}$.

$$
k_{S}=1.3 h_{P V A}
$$

\section{References}

50) Hoerner, S. F.: "Fluid-Dynamic Drag", published by the author, New York, (1965).

51) Nara, J.: "Instruments for Surface Roughness", The Daily Industrial News Co., ltd., Tokyo, (1968). 